\title{
Antioxidant and immune responses of broiler chickens supplemented with Rhazya stricta extract in drinking water
}

\author{
Saleh M. Albarrak iD \\ Department of Veterinary Medicine, College of Agriculture and Veterinary Medicine, Qassim University, Buraydah, Saudi \\ Arabia. \\ Corresponding author: Saleh M. Albarrak, e-mail: sale7co@hotmail.com \\ Received: 02-01-2021, Accepted: 19-04-2021, Published online: 04-06-2021
}

doi: www.doi.org/10.14202/vetworld.2021.1437-1449 How to cite this article: Albarrak SM (2021) Antioxidant and immune responses of broiler chickens supplemented with Rhazya stricta extract in drinking water, Veterinary World, 14(6): 1437-1449.

\begin{abstract}
Background and Aim: Rhazya stricta is a herbal plant widely used in traditional medicine due to its proficiency and naturalness with few side effects. In this study, we investigated the impact of using an $R$. stricta extract supplement on broiler chickens' performance, especially the immune system.

Materials and Methods: In addition to the control group, one group received the methanol extract of $R$. stricta in drinking water for the first 2 weeks before being challenged with sheep erythrocytes (SRBCs), while the other group was challenged with SRBCs without receiving the $R$. stricta treatment. We evaluated cellular immunity by determining the phagocytic activity and lymphocyte (L) proliferation and assessed humoral immunity by quantification of the serum total IgM and IgG. We measured the serum levels of antioxidant enzymes and performed a histological examination of the spleen and the bursa of Fabricius (BF).

Results: Our results indicate a significant enhancement in cellular immunity in the group supplemented with $R$. stricta as demonstrated by a significant increase in the phagocytic activity, $L$ proliferation, and percentages of circulating $\mathrm{L}(\mathrm{p}<0.05)$. The chickens treated with $R$. stricta exhibit an enhanced humoral response shown by a significant elevation in the serum levels of the total antibodies of the $\operatorname{IgM}$ and IgG isotypes, along with a notable increase in BF activity. Furthermore, $R$. stricta supplementation is associated with a significant increase in the serum levels of catalase and superoxide dismutase $(\mathrm{p}<0.05)$, along with a significant improvement in broilers' general performance, body weight, and feed efficiency.
\end{abstract}

Conclusion: Our results suggest an immunomodulatory effect for the methanol extract of $R$. stricta and highlight the potential use of this plant in preventive and therapeutic medicine.

Keywords: antioxidants, chickens, immunomodulation, Rhazya stricta.

\section{Introduction}

The utilization of conventional medicine is the backbone of essential medicinal services, especially in developing nations. The use of natural medication in the developed world also is increasing. More people are turning toward traditional medicine, which they believe has fewer harmful and adverse reactions than do Western medications. Beneficial (medicinal) plants remain the source of life-sparing remedies for the majority of people worldwide.

Bioactive constituents derived from plants are utilized as nourishment-added substances, colors, insect repellents, beautifying agents, and perfumes. These compounds are collectively known as secondary metabolites. About $80 \%$ of the human population depends on medicinal plants to maintain their well-being and to treat sickness. With the increasing interest in medicinal plants as a source of medication, examining new plants with known therapeutic properties

Copyright: Albarrak. Open Access. This article is distributed under the terms of the Creative Commons Attribution 4.0 International License (http://creativecommons.org/licenses/by/4.0/), which permits unrestricted use, distribution, and reproduction in any medium, provided you give appropriate credit to the original author(s) and the source, provide a link to the Creative Commons license, and indicate if changes were made. The Creative Commons Public Domain Dedication waiver (http://creativecommons.org/ publicdomain/zero/1.0/) applies to the data made available in this article, unless otherwise stated. used either in modern or traditional medicine is necessary [1].

Remedial plants are widely utilized in Saudi Arabia because of their natural proficiency without side effects. Indeed, even some herbal plants, including Rhazya stricta, have for many years been used to regulate immune responses, with their mechanisms of action still unknown. $R$. stricta, locally called Harmal, belongs to the Apocynaceae family and is broadly distributed in the Middle East and the northwestern part of the Indian sub-continent [2]. R. stricta is a significant therapeutic plant in Saudi Arabia, growing in the desert regions of the Arabian Peninsula [3].

$R$. stricta is broadly used in traditional medicine to treat illness [4,5], as it is a rich source of terpenoid indole alkaloids and contains glycosides, alkaloids, flavonoids, tannins, and triterpenes [6]. R. stricta has been used to relieve malignant growths (cancer) [7], diabetes [8], irritation, and infections [6]. Its more than 100 alkaloids [9] have anti-inflammatory, antidepressant, herbicidal, and antifungal properties [7]. Seed oil from $R$. stricta contains a high amount of d-tocopherol, a significant source of Vitamin E [10].

Recently, a few flavonoid compounds have been derived from $R$. stricta gathered from various regions of Saudi Arabia [4]. The biological activities 
of $R$. stricta are due to the alkaloids rhazimine, strictanol, sewarine, and tetrahydrosecaminediol, which have numerous capacities as antioxidants, antifungals, and antimicrobials and can affect glucose homeo-balance, blood pressure, the nervous system, and arachidonic acid metabolism [9]. In addition, $R$. stricta can be used as an antihelminthic and anti-inflammatory agent and to treat chronic rheumatism and sore throat [11]. In mice, the alkaloid extracts of $R$. stricta have been shown to improve liver function and protect liver tissue from paracetamol [12]. R. stricta also is widely used to treat diabetes either alone or as an adjuvant medication [13]. One study has found that $R$. stricta induces the killing of breast cancer cells through apoptosis [14]. Many alkaloids derived from $R$. stricta can suppress the proliferation of different types of tumors in vivo and in vitro [6].

Free radicals can decrease the antioxidants of the immune system and alter gene expression, which may lead to the production of abnormal proteins. Antioxidant agents are used to counterbalance the effects of free radicals, protecting against degenerative illnesses. Antioxidant agents are grouped into two major classifications: Natural and synthetic. Butylated hydroxytoluenes, butylated hydroxyanisole (BHA), tertiary butylated hydroquinone, and gallic acid (GA) esters are examples of synthetic antioxidants. These antioxidants can successfully hinder oxidation; can fill in as chelating specialists (e.g., ethylene diamine tetra-acetic acid [EDTA]); and can bind to metals, decreasing their involvement in the process [15].

Synthetic antioxidants are thought to cause or advance negative effects on human health (e.g., mutagenesis and carcinogenesis) [16]. Replacing manufactured antioxidants with natural agents can protect from free-radical-related disorders [15]. Natural antioxidants can control the production of free radicals and inhibit their actions in the biological systems [17]. These antioxidants contain antioxidative enzymes (e.g., superoxide dismutase [SOD], glutathione peroxidase [GSH-PX], and catalase [CAT]) and also non-enzymatic components (e.g., GSH and nutrients $\mathrm{C}$ and E) [18]. Many plant extracts contain antioxidant agents [19].

Arachidonic acid metabolism in human blood is inhibited by rhazimine, an alkaloid extracted from $R$. stricta leaves [20]. The lyophilized extract of $R$. stricta has been shown to have an antispasmodic impact on rodent muscles [21]. In one investigation, the antioxidant effects appeared at higher dosages, diminishing the hepatic and renal levels of GSH and elevating the levels of ascorbic acid, although the levels of lipid peroxidation were decreased [22]. Another study examining biochemical parameters in rats, such as liver enzymes, blood lipid profile, and kidney functions [23], found that the fluid extract of $R$. stricta and indole alkaloids significantly increased the levels of serum adiponectin and significantly increased insulin resistance [24].
Multiple studies have demonstrated that the alkaloid extract of $R$. stricta leaves restrained multiplication, colonization, and development of different cancer cell lines (e.g., colon and lung cancers) [25]. $R$. stricta has for some time been utilized in regulating immune responses, with its mechanism of action still unknown. Immunomodulation includes the ability to promote or suppress the immune system [26].

To the best of our knowledge, no study has examined the effects of $R$. stricta supplementation on the performance of the immune system in poultry (chicken). Therefore, this study investigated the humoral and cellular immune responses in broiler (Ross) chickens supplemented with the methanol extract of $R$. stricta in drinking water for the first 2 weeks of life. In addition, we examined the effects of the extract on body weight, daily weight gain, daily feed consumption, and feed conversion ratio. To complete the assessment, we performed a leukogram and histological examination of the spleen and bursa of Fabricius (BF), as well as measured the serum levels of antioxidative enzymes, such as SOD, CAT, and GSH-PX. We evaluated the indicator parameters from Day 1 to Day 42 in a well-controlled experiment done in the chicken housings at the Agricultural and Veterinary Research Station at Qassim University.

\section{Materials and Methods}

\section{Ethical approval}

All the procedures done on broilers were permitted by Qassim University, Saudi Arabia (No. 2332).

\section{Study period and location}

The study was conducted from 10-10-2019 to 21-11-2019 (six weeks) in the chicken housing facility at the Agricultural and Veterinary Research Station of Qassim University.

\section{Plant extract}

$R$. stricta plants were collected from their original territories by Fischer S., \#97, in Saudi Arabia from the herbarium collection of Martius during blooming season from winter to spring. The aerial plant pieces were washed with tap water, air-dried, crushed, and then extracted. A total of $200 \mathrm{~g}$ of the powdered plant was mixed with $2 \mathrm{~L}$ of methanol (99.9\%), agitated and left for $72 \mathrm{~h}$, and filtrated; the filtrate was placed in clean containers. This process was repeated multiple times until clear filtrate was acquired. Under reduced pressure using a rotary evaporator (BUTCHI, Switzerland), the methanol extracts were concentrated at a temperature not exceeding $50^{\circ} \mathrm{C}$, and the yield rates were recorded. The concentrated extract was stored at $4^{\circ} \mathrm{C}$ until use.

\section{Extract preparation}

A total of $20 \mathrm{mg}$ of the plant powder was resuspended with $100 \mathrm{~mL}$ of methanol (99.9\%) and left for $24 \mathrm{~h}$. Using Whatman No. 1 filter paper, the methanol extract was then purified, and the residue was removed. Sodium sulfate was used for dehydration to remove the traces of moisture [27]. 
Gas chromatography-mass spectral analysis (GC-MS)

Analysis of the methanol extracts using GC-MS was done following a method described by Soumya et al. [27] utilizing Agilent GC (Model 6890N coupled to 5973 Mass Selective Detector, USA). To confirm the presence of phytochemicals, the results were compared with an in-built main library (NIST08.L). GC-MS was fortified with Elite-5 ms (5\% diphenyl/95\% dimethylpolysiloxane), $30 \mathrm{~mm} \times 0.25 \mathrm{~mm} \times$ $0.25 \mu \mathrm{m} \mathrm{df}$.

For GC-MS detection, the electron ionization energy of $70 \mathrm{eV}$ was used with absolute helium gas as the carrier at a fixed current rate of $1 \mathrm{~mL} / \mathrm{min}$. An injection capacity of $2 \mu \mathrm{l}$ was engaged (split ratio 10:1) with an automatic temperature of $250^{\circ} \mathrm{C}$ and ion source temperature maintained at $200^{\circ} \mathrm{C}$. The oven temperature was modified from $110^{\circ} \mathrm{C}$ (isothermal for $2 \mathrm{~min}$ ), with an increase of $10^{\circ} \mathrm{C} / \mathrm{min}$, to $200^{\circ} \mathrm{C}$, then $5^{\circ} \mathrm{C} / \mathrm{min}$ to $280^{\circ} \mathrm{C}$ for a $9-\mathrm{min}$ isothermal time. Mass spectra were taken at $70 \mathrm{eV}$, with a scan interval of $0.5 \mathrm{~s}$ and pieces from 45 to $450 \mathrm{Da}$. The complete $\mathrm{GC}-\mathrm{MS}$ running time was $36 \mathrm{~min}$. The relative $\%$ of every integral was calculated by contrasting its average top area with the total areas with software modified to deal with mass spectra and chromatograms.

\section{Total phenolic content (TPC)}

A gram of dried sample was reconstituted with $25 \mathrm{~mL}$ of methanol $(70 \%)(\mathrm{v} / \mathrm{v})$. The suspensions were agitated actively in a shady container for $100 \mathrm{~min}$ at $100 \mathrm{rpm}$, followed by centrifugation for $10 \mathrm{~min}$ at $3225 \mathrm{~g}$. The supernatant was collected, and the pellet was re-extracted doubly with $15 \mathrm{~mL}$ of methanol $(70 \%)$ for determination of the TPC and antioxidant activity. The extract was saved in the dark at $-20^{\circ} \mathrm{C}$, and analysis was done within $48 \mathrm{~h}$ to avoid oxidation. The TPC was measured according to the FolinCiocalteu spectrophotometric analysis; the results were linked to a standard curve of previously organized GA solution [28]. TPC was shown as mg of GA equivalents (GAEs) per gram of dried powder ( $\mathrm{mg}$ of GAE $\left.\mathrm{g}^{-1} \mathrm{dw}\right)$.

1,1-dipheny1-2-picrylhydrazyl (DPPH) scavenging activity assay (determination of antioxidant activity)

The DPPH reagent DPPH was utilized to determine the fundamental scavenging activity for the dried sample extract using a method modified by Lu et al. [28]. A total of $0.1 \mathrm{~mL}$ of the sample was mixed with $2.9 \mathrm{~mL}$ of $6 \times 10^{-5} \mathrm{~mol}$ of DPPH (methanolic solution). The mixture was kept in the dark place for $1 \mathrm{~h}$ and read the absorbance at $517 \mathrm{~nm}$. The Trolox calibration curve was constructed as a function of DPPH radical scavenging activity (RSA) and expressed in \%. The obtained data were shown as $\mu$ mol of Trolox equivalent (TE) per gram of sample ( $\left.\mu \mathrm{mol} \mathrm{TE} \mathrm{g}^{-1} \mathrm{dw}\right)$.

\section{Experimental chickens and housing}

One-day-old chicks (Ross broilers; $n=90$ ) were provided by the Al Watania Poultry Company
(Al-Qassim, Saudi Arabia). Each chick's average weight was calculated by dividing the total weight of all the chicks by their total number. Chicks were housed in suitable housing rooms at the Agricultural and Veterinary Experiment Station, Qassim University, Saudi Arabia, in optimal rearing conditions. Feed and water were provided as desired, and the housing facility had a Dicam FSC 2.2 m master unit (Farm Energy and Control Services Lid "Farmex," Pinewood, Reading RG 303VR, UK) for controlling the ventilation and temperature in each room.

\section{Chicken feed}

Two different feeds were provided by the Al Watania Poultry Company, which included broiler starter and finisher rations formulated to provide the recommended nutritional requirements for broilers according to the National Research Council (Table-1) [29]. The starter feed was given to the chicks from age Day 1 to Week 4, when it was replaced with the finishing feed until the end of the experiment. The feed was soybeans and corn free of antibiotics or growth hormones.

\section{Experimental design}

The chicks were randomly divided into three groups of 30 birds each. The first group was fed the starter and finisher rations (the control group). The second group was fed the starter and finisher rations and challenged with sheep erythrocytes (SRBCs; the SRBC-challenged group). The third group was given the starter and finisher rations plus the SRBC and the $R$. stricta concentrated extract in the water (only for the first 2 weeks of life; considered the treatment group, the $\mathrm{SRBC}+R$. stricta group). Considering the rate of daily water consumption, the recommended dose of the extract was $18 \mathrm{mg} / \mathrm{chick}$ [30]. SRBCs were used as a foreign antigen to quantify the humoral response.

A total of $30 \mathrm{~mL}$ of whole blood from a healthy young ewe was collected into sterile tubes containing equal amounts of Alsever's solution, 0.1 molar pH 6.1. The blood samples were centrifuged at $900 \mathrm{~g}$ for $10 \mathrm{~min}$ to pellet the blood cells. The cells were washed 3 times with phosphate-buffered saline (PBS) $(\mathrm{pH} 8)$ and suspended in PBS to $1 \%$ concentration to be injected in the chicks [31]. The SRBC-challenged group was injected intramuscularly with $0.5 \mathrm{~mL}$ of $1 \%$ SRBC at Days 14 and 28.

\section{Broiler performance}

Multiple parameters were used to assess broiler performance, including body weight, weekly weight

Table-1: Proximat analysis of crude protein, crude fat, and crude fiber percentages of the starter mash and crumbs diets.

\begin{tabular}{ll}
\hline \multicolumn{2}{c}{ Calculated analysis } \\
\hline Starter & Grower-Finisher \\
\hline Crude Protein (Min) $21.5 \%$ & Crude Protein (Min) $18.5 \%$ \\
Crude Fat (Min) $2.5 \%$ & Crude Fat (Min) $3.0 \%$ \\
Crude Fiber (Max) $3.5 \%$ & Crude Fiber (Max) $3.5 \%$ \\
\hline
\end{tabular}


gain, daily feed consumption, and feed conversion ratio. Chicks in each group were weighed totally and weekly until the end of the experiment at 6 weeks of age. The feed given to each group was recorded daily with an automatic weighing device. Feed residues were weighed at the end of each week. Therefore, feed consumption was noted on a weekly basis and calculated as feed consumed per week over 6 weeks. The feed conversion ratios were then calculated for weeks 2, 3, 4, 5, and 6 .

\section{Blood sampling}

Blood samples were collected from at least 3 birds/group on days 14,28 , and 42 through the jugular vein into plain tubes. The blood samples were centrifuged at $900 \mathrm{~g}$ for $10 \mathrm{~min}$ and left to clot for overnight at $4^{\circ} \mathrm{C}$. The serum was aspirated and preserved in sterile tubes at $-20^{\circ} \mathrm{C}$ until use.

\section{Serum levels of SOD, CAT, and GSH-PX}

The antioxidant activity was determined by measurement of GSH-PX, SOD, and CAT (Biodiagnostic Kits, CAT. Nos. 2579, 2563, and 2511, respectively).

\section{In vitro carbon clearance assay}

Phagocytic activity was evaluated using the in vitro carbon clearance assay [32]. Blood was collected on days 14,28 , and 42 in tubes containing an anticoagulant (heparin). A total of $6 \mu \mathrm{L}$ of India ink (Pelikan AG D-3000, Hanover, Germany) was added to each blood sample ( $6 \mu \mathrm{L}$ ink $/ 1.5 \mathrm{~mL}$ of blood). The mixture sample was split into three aliquots containing $0.5 \mathrm{~mL}$ each to be incubated at $37^{\circ} \mathrm{C}$ for 20 and $40 \mathrm{~min}$. Following incubation, $150 \mu \mathrm{L}$ of each mixture was diluted with $2 \mathrm{~mL}$ of saline and centrifuged at $50 \mathrm{~g}$ for $4 \mathrm{~min}$. The supernatants were collected and measured by a spectrophotometer at $535 \mathrm{~nm}$, with the background used as 0 . The data of the optical density were transformed to a $\log _{2}$ scale, and the phagocytic index was calculated as the negative of the slope of the regression of optical density $\left(\log _{2}\right)$ on time (h).

\section{Glucose consumption assay}

Autoclaved red blood cell (RBC) lysis buffer composed of $\mathrm{NH} 4 \mathrm{Cl}(0.155 \mathrm{M}) 90 \mathrm{~g}, \mathrm{KHCO}_{3}(0.01 \mathrm{M})$ $10 \mathrm{~g}$, and EDTA $(0.1 \mathrm{mM}) 370 \mathrm{mg}$ dissolved in $1 \mathrm{~L}$ of $\mathrm{ddH} 2 \mathrm{O}$ was used to remove or lyse the RBCs to isolate leukocytes. Lysis buffer was diluted 1:10 in $\mathrm{ddH} 2 \mathrm{O}$ and passed through a $0.22-\mu \mathrm{m}$ filter before use. Whole blood $(200 \mu \mathrm{L})$ was mixed with $2 \mathrm{~mL}$ of lysis buffer, incubated at room temperature $\left(28-30^{\circ} \mathrm{C}\right)$ for $5 \mathrm{~min}$, and centrifuged at $300 \times \mathrm{g}$ to remove the lysis buffer.

Lymphocyte (L) proliferation was performed using the glucose consumption test as reported by Kosti et al. [33]. Phytohemagglutinin (PHA), a T cell mitogen, was used in this assay. Using a 24-well plate, cells were seeded in triplicate in the presence or absence of $5 \mu \mathrm{g} / \mathrm{mL}$ PHA. Each well had $200 \mu \mathrm{L}$ of culture medium (RPMI Cat\# R6504, Sigma-Aldrich, St. Louis, MO, USA) containing $2 \times 10^{6}$ cells. The plate was incubated at $37^{\circ} \mathrm{C}$ in a humidified $5 \% \mathrm{CO}_{2}$ incubator for $72 \mathrm{~h}$. Using assay kits (Human $\mathrm{GmbH}, 65205$ Wiesbaden, Germany) glucose levels were quantified in the medium by observing the variation in the optical density at $500 \mathrm{~nm}$. L proliferation was measured as the amount of the consumed glucose $(\mathrm{mg} / \mathrm{dL})$ minus the glucose level in the non-stimulated cell culture.

\section{Antibody quantification}

Total antibody titer for the IgM and IgG isotypes was determined using commercial isotype immunoglobulin (Ig), chicken-specific Sandwich ELISA Kits according to the manufacturer's specifications (SunLong Biotech Co. Ltd., HangZhou, China).

\section{Leukogram}

$\mathrm{N} \%, \mathrm{~L} \%$, and $\mathrm{N}$ : $\mathrm{L}$ ratios were counted by the cross-sectional method described by Jain [34]. The number of leucocytes counted/slide was 100, and the counted cells were presented as $\%$.

\section{Relative weights and histopathology of lymphoid} organs (BF and spleen)

A total of three birds from each group were euthanized on days 14,28 , and 42 . Total body weights were determined; the birds were opened, and the BF and spleen were carefully removed and weighed separately. The relative weights of the different organs were calculated as $\%$ of live body weight.

The collected BF and spleen tissue specimens were immediately fixed in $10 \%$ neutral buffered formalin and embedded in paraffin wax. Thin sections of 4-5 $\mu \mathrm{m}$ in thickness were then processed and stained with hematoxylin and eosin ( $\mathrm{H}$ and $\mathrm{E})$ to examine the changes microscopically according to a method previously described [35].

\section{Statistical analysis}

We assigned the obtained results for statistical analysis using GraphPad Prism version 5 software (GraphPad Software, San Diego, CA, USA). We used analysis of variance to detect significant variations among the groups. For significant differences, we performed the Student-Newman-Keuls test. We recorded all data separately.

\section{Results}

\section{Chemical composition of $R$. stricta}

We detected signal peaks associated with segregated constituents by GC-MS in the $R$. stricta extract (Figure-1B). Composites greater than $1 \%$ are listed in Table-2. Aspidospermidine (28\%), uleine (11.76\%),

Table-2: Compounds detected by area from Rhazya stricta extract.

\begin{tabular}{lcc}
\hline Name & Peak \% area & RT \\
\hline Aspidospermidine & 28 & 17.626 \\
Uleine & 11.76 & 22.21 \\
2-Hexadecanol & 9.27 & 11.575 \\
3-O-Methyl-d-glucose & 6.84 & 11.166 \\
Squalene & 3.59 & 25.654 \\
d-Mannose & 3.13 & 10.829 \\
\hline
\end{tabular}


2-hexadecanol $\quad(9.27 \%), \quad 3$-o-methyl-d-glucose $(6.84 \%)$, squalene $(3.59 \%)$, and d-mannose $(3.13 \%)$ were the major components present in the extract and were considered to be $50 \%$ of its composition.

\section{TPC and antioxidant activity of $R$. stricta}

We spectrophotometrically determined the TPC of the R. stricta extract, presenting the data as $\mathrm{mg}$ of GAE per $g$ of the dried $R$. stricta sample. As shown in Figure-1A, the amount of TPC present in the extract was high, reaching $301.99 \pm 8.79 \mathrm{mg} \mathrm{GAE} \mathrm{g}^{-1}$ of the sample. We also assessed the antioxidant activities of the extract using the DPPH reagent DPPH to measure the BPPH-RSA of the dried sample. As shown in
Figure-1A, our results indicate that the DPPH-RSA for the $R$. stricta extract was $38.05 \pm 6.58 \mu \mathrm{mol}$ of TE $\mathrm{g}^{-1}$.

\section{Body weight gain and feed conversion rate}

The body weight gain in the $\mathrm{SRBC}+R$. stricta chicks significantly increased $(\mathrm{p}<0.05)$ over that of the chicks in the control group. The feed conversion rate tended to be lower in the control group $(1.44 \pm 0.33)$ as compared to the SRBC-challenged and $\mathrm{SRBC}+R$. stricta groups $(1.40 \pm 0.39$ and $1.32 \pm 0.16$, respectively) (Table-3).

\section{Serum antioxidant enzymes}

We determined the serum antioxidant enzyme activities in the different groups of chicks (Figure-2).

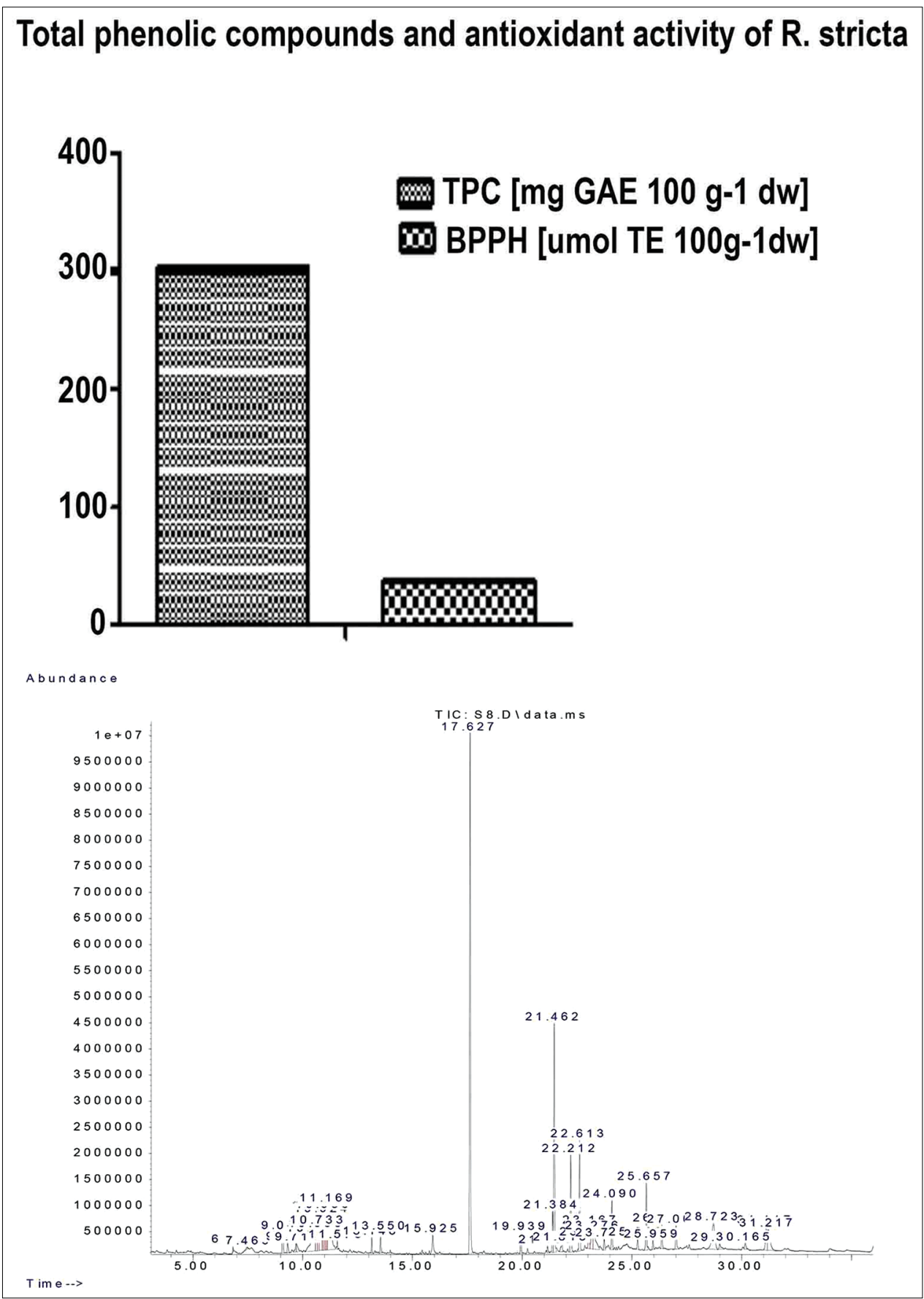

Figure-1: Total phenolic compounds and antioxidant activity of Rhazya stricta (A) chromatogram of the methanolic extract of $R$. stricta (B). dw: Dry weight, *: DPPH radical scavenging activity (BPPH-RSA). 
Table-3: Body weight gain, individual feed consumption, and feed conversion of chickens challenged with sheep erythrocytes following pretreatment with the Rhazya stricta extract.

\begin{tabular}{lccccc}
\hline Groups & $\begin{array}{c}\text { Initial body } \\
\text { weight (g) }\end{array}$ & $\begin{array}{c}\text { Final body } \\
\text { weight (day 42) }\end{array}$ & $\begin{array}{c}\Delta \text { body weight } \\
\text { (body gain) }\end{array}$ & $\begin{array}{c}\text { Individual feed } \\
\text { consumption }\end{array}$ & Feed conversion \\
\hline Control & $45.01 \pm 2.54$ & $3111 \pm 8.22$ & $3066.0 \pm 5.76$ & $4405.9 \pm 8.97$ & $1.44 \pm 0.33$ \\
SRBC & $45.72 \pm 3.11$ & $3191 \pm 7.13$ & $3145.4 \pm 6.23$ & $4414.9 \pm 4.08$ & $1.40 \pm 0.39$ \\
Rhazya stricta + SRBC & $44.85 \pm 2.09$ & $3417 \pm 6.99$ & $3372.2 \pm 4.98^{\text {a }}$ & $4452.9 \pm 6.99$ & $1.32 \pm 0.16$ \\
\hline
\end{tabular}

Mean \pm Standard error. Values within the same day having the letter ${ }^{a}$ is significantly different from the control value at $\mathrm{p}<0.05$

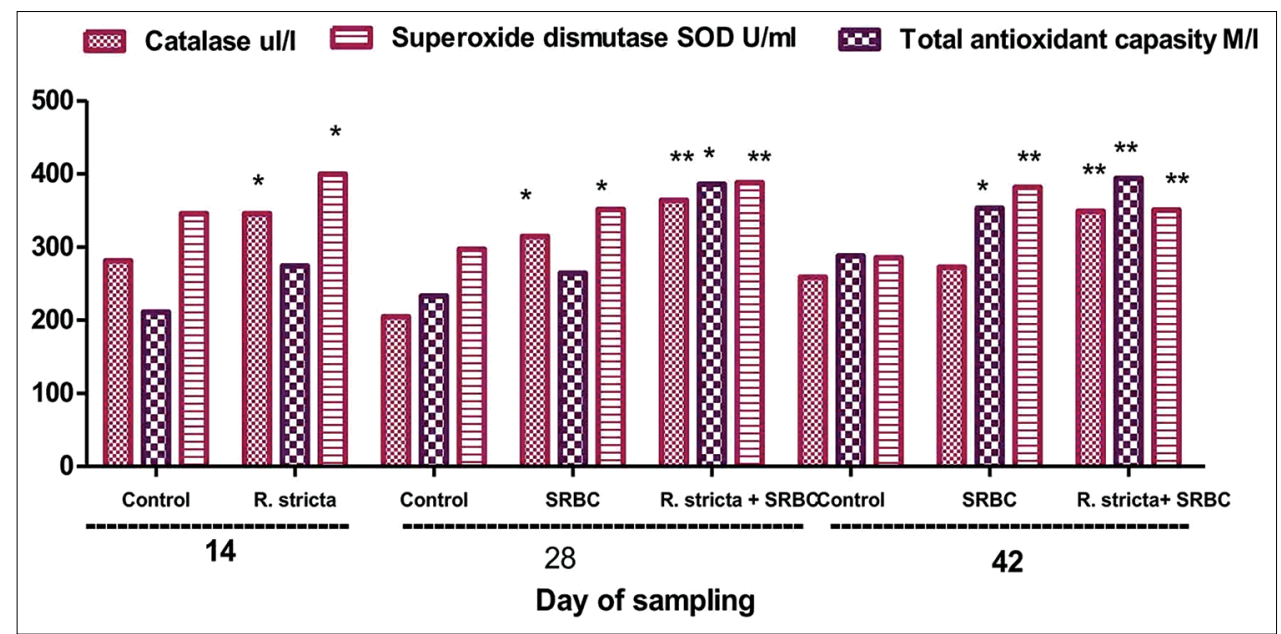

Figure-2: Serum antioxidant enzymes of chickens supplemented with Rhazya stricta extract and challenged with sheep erythrocytes. Values within the same day having the marks $*, * *, * * *$ are significantly different from the control value at $\mathrm{p}<0.05, \mathrm{p}<0.01$, and $\mathrm{p}<0.001$, respectively. Mean \pm Standard error.

The results showed a significant increase in the serum activities of CAT $(\mathrm{p}<0.01)$ and SOD $(\mathrm{p}<0.05)$ in the $\mathrm{SRBC}+R$. stricta chicks. For the SRBC-challenged chicks, serum CAT and SOD activities were significantly elevated $(\mathrm{p}<0.05)$ as compared to those in the control chicks.

We noted a significant increase in the serum activitiesofCAT $(\mathrm{p}<0.001)$, totalantioxidantcapacity $(\mathrm{p}<0.05)$, and SOD $(\mathrm{p}<0.01)$ on day 28 in the SRBC+R. stricta group as compared to the control group. We observed a significant elevation in serum activities of total antioxidant capacity $(\mathrm{p}<0.05)$ and SOD $(\mathrm{p}<0.01)$ on day 42 in the SRBC-challenged chicks as compared to the control chicks. In addition, we noted a significant increase in serum activities of CAT $(p<0.001)$, total antioxidant capacity $(p<0.01)$, and SOD $(p<0.01)$ in the chicks at the end of the experiment (Day 42) in the SRBC $+R$. stricta and SRBC-challenged groups.

\section{Phagocytic activities}

We determined the in vitro phagocytic index of chicks on days 14,28 , and 42 following supplementation with the $R$. stricta extract and challenge with SRBCs (Figure-3). The results showed a significant increase in the in vitro phagocytic index $(\mathrm{p}<0.05)$ of the $\mathrm{SRBC}+R$. stricta chicks on day 14 as compared to the control chicks. On day 28 , the phagocytic index was significantly elevated $(\mathrm{p}<0.01)$ in the $\mathrm{SRBC}+R$. stricta group relative to the control group. The index significantly increased on day 42 in the SRBC-challenged group $(p<0.01)$ as well as in the
$\mathrm{SRBC}+R$. stricta group $(\mathrm{p}<0.001)$ as compared to the control group.

\section{L proliferation determined by glucose consumption}

As shown in Figure-4, our results showed that the amount of glucose consumed by Ls was significantly higher in the SRBC-challenged chicks $(p<0.05)$ as compared to the control chicks. Similarly, Ls obtained from $\mathrm{SRBC}+R$. stricta chicks consumed a significantly higher amount of glucose as compared to Ls in the control chicks $(\mathrm{p}<0.001)$.

\section{Leukogram}

Our results revealed a significantly higher $\mathrm{L} \%(\mathrm{p}<0.05)$ and lower $\mathrm{H} / \mathrm{L}(\mathrm{p}<0.05)$ on day 14 in $\mathrm{SRBC}+R$. stricta chicks relative to the control chicks. However, we noted similar observations on days 28 and 42 . We observed a significant increase in $\mathrm{L} \%, \mathrm{H} \%$, and $\mathrm{M} \%(\mathrm{p}<0.05)$ on day 28 and a significant increase $(\mathrm{p}<0.05)$ in TLC and M\% in the SRBC-challenged chicks as compared to the control chicks (Figure-5).

\section{Total IgM and total IgG titers}

We determined the titers of the total IgG and IgM at different times during the experiment using the ELISA technique (Figure-6). On day 14, we observed a significant increase in the concentrations of total $\operatorname{IgM}$ in the $\mathrm{SRBC}+R$. stricta group as compared to the control group $(p<0.05)$. After the challenge with SRBC, the concentrations of total IgG significantly increased on day 21 as compared to the control group $(\mathrm{p}<0.01)$, with the IgM concentrations remaining 


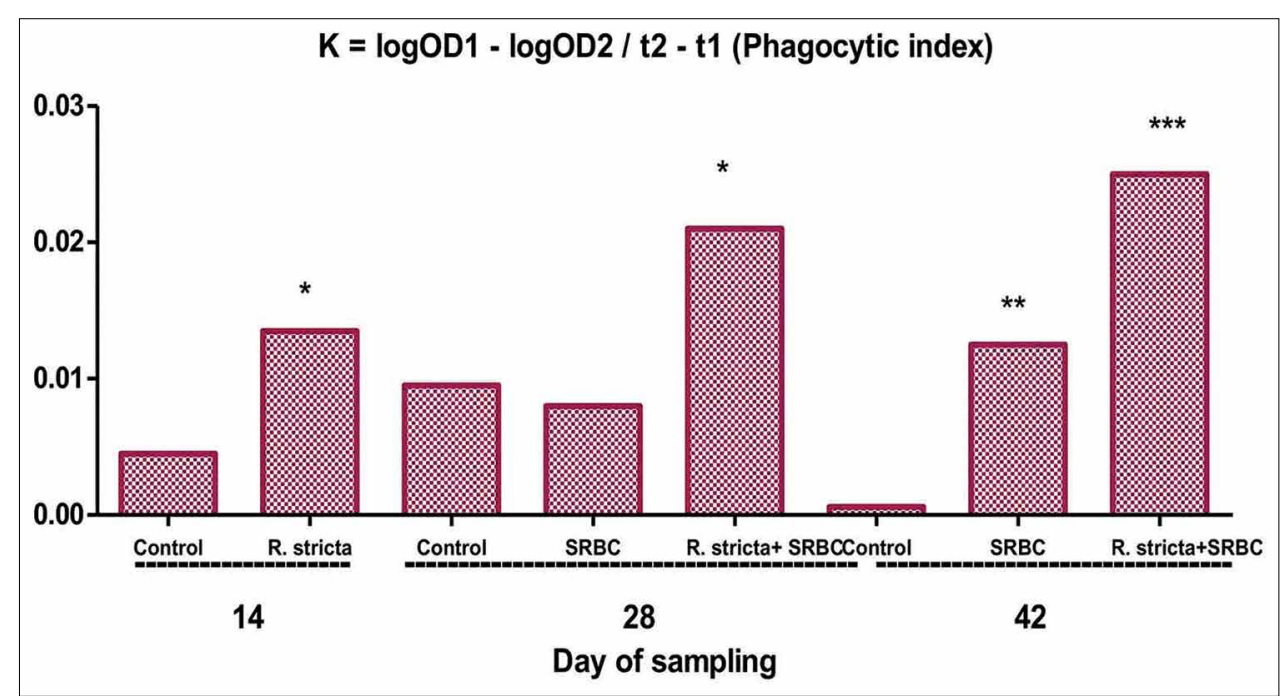

Figure-3: In vitro phagocytic index of chickens supplemented with the Rhazya stricta extract and challenged with sheep erythrocytes. Values within the same day having the marks $*, * *, * * *$ are significantly different from the control value at $\mathrm{p}<0.05, \mathrm{p}<0.01$, and $\mathrm{p}<0.001$, respectively. Mean \pm Standard error.

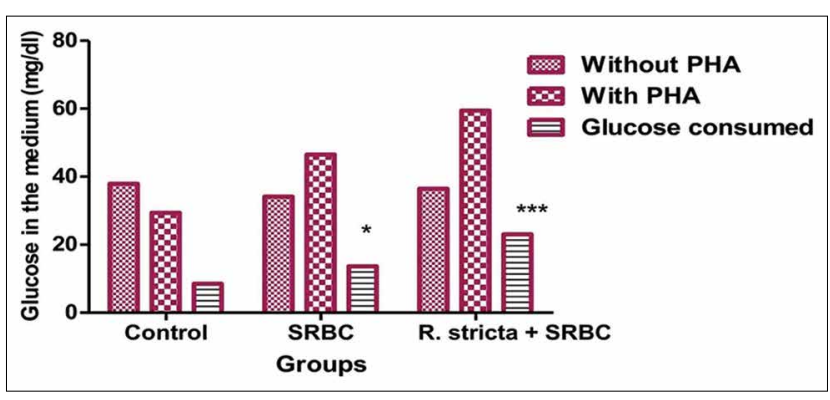

Figure-4: Glucose consumed $(\mathrm{mg} / \mathrm{dL})$ by lymphocytes stimulated with phytohemagglutinin of chickens pretreated with Rhazya stricta and challenged with sheep erythrocytes. Values within the same day having the marks $*, * *, * * *$ are significantly different from the control value at $p<0.05$, $p<0.01$, and $p<0.001$, respectively. Mean \pm Standard error.

significantly elevated only in the $\mathrm{SRBC}+R$. stricta group $(\mathrm{p}<0.05)$. The levels of total IgG were significantly higher in the SRBC $+R$. stricta group $(\mathrm{p}<0.01)$ on day 28 and in both the SRBC-challenged $(\mathrm{p}<0.001)$ and the $\mathrm{SRBC}+R$. stricta $(\mathrm{p}<0.01)$ groups on day 42 as compared to the control group.

\section{Relative weights and histology of BF and spleen}

The $\mathrm{BF}$ weights in the $\mathrm{SRBC}+R$. stricta chicks were significantly increased $(\mathrm{p}<0.05)$ on day 14 as compared to those in the control chicks. On day 28 , the weights of both spleen $(p<0.05)$ and BF $(p<0.05)$ were significantly higher in the $\mathrm{SRBC}+R$. stricta group as compared to those of the control group. At the end of the experiment (day 42), our data showed a significant increase in the weights of both spleen $(p<0.01)$ and $\mathrm{BF}(\mathrm{p}<0.05)$ in each of the $\mathrm{SRBC}+R$. stricta and SRBC-challenged groups relative to the control group (Figure-7).

In the control group, the histological examination of tissue sections of the spleen stained by $\mathrm{H}$ and $\mathrm{E}$ showed normal histological structures at all ages. As age advanced from day 14 to day 42, different types of splenic nodules were easily visible, as were different types of red and white pulp (Figure-8). In the SRBCchallenged chicks, histological examination of the spleen revealed that the white pulp increased and was easily seen on day 42 as compared to day 28 . We noticed that the white pulp increased and the splenic nodules were easily visible in the $\mathrm{SRBC}+R$. stricta chicks as they aged. In addition, the red and white pulp were easily demarcated (Figure-8).

The histological examination of the BF in the control chicks on days 14,28 , and 42 stained by $\mathrm{H}$ and $\mathrm{E}$ showed numerous lymphoid follicles on day 14. The follicles are comprised of the cortex and the medulla. The corticomedullary border, which separates the medulla from the cortex, contained undifferentiated cells and blood capillaries. The connective tissue and blood capillaries were present in the cortex but not in the medulla. A smooth muscular layer rests under the mucosa enclosed by the T. serosa.

On day 28, BF follicles appeared large and densely populated. The cortex was separated from the medulla by a basal membrane, visible in most sections. On day 42, BF follicles appeared small and densely populated with scattered vacuolation (Figure-9). We noticed that the medulla of the BF of the SRBC-challenged chicks showed a moderate population of Ls, especially on day 42 (Figure-10). The $\mathrm{BF}$ of the $\mathrm{SRBC}+R$. stricta chicks showed the medulla with an extensive population of Ls, especially on Day 42 (Figure-11).

\section{Discussion}

This study evaluated the humoral and cellular immune responses of broiler chickens following supplementation with the ethanol extract of $R$. stricta in drinking water. The assessment of the humoral immunity included quantification of antibody production as well as histological examination of the BF. We evaluated the effects of the R. stricta extract on cellular immunity with leukograms, in vitro phagocytic index, 


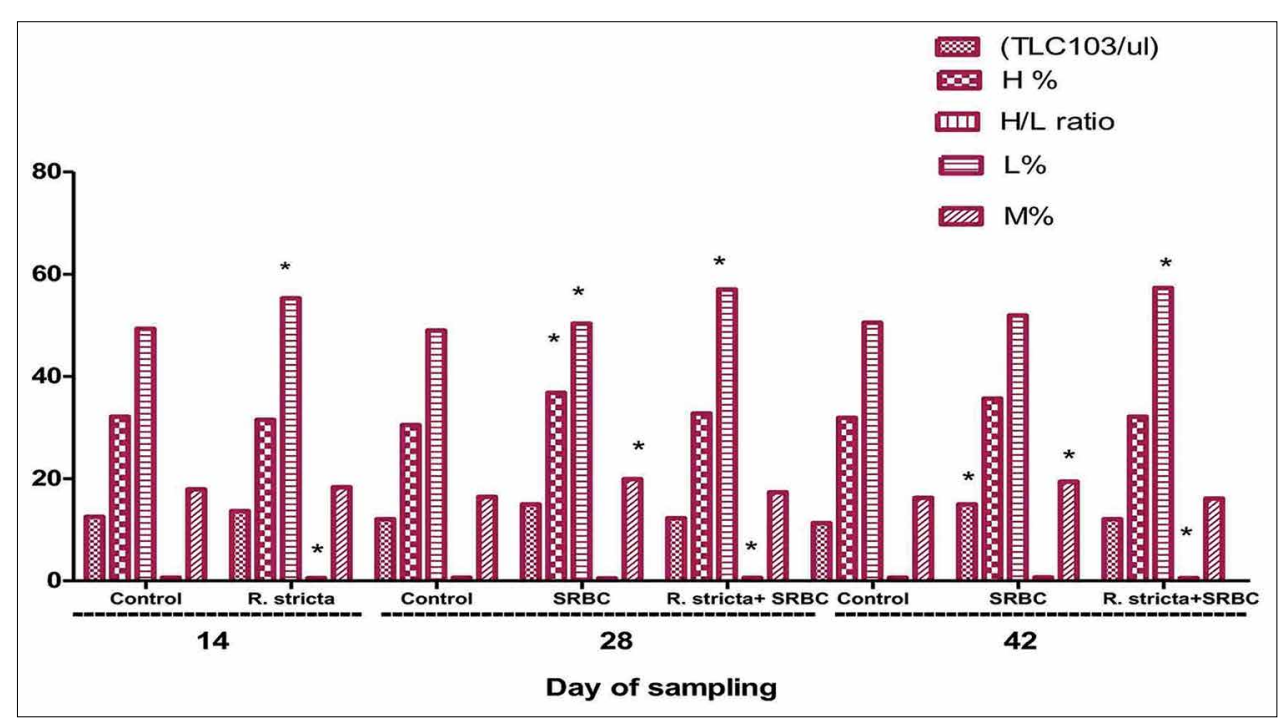

Figure-5: Total leukocytes count $\left(10^{3} / \mathrm{mm}^{3}\right)$; heterophils $(\mathrm{H} \%)$; lymphocyte $(\mathrm{L} \%)$, monocyte $(\mathrm{M} \%)$ and $\mathrm{H} / \mathrm{L}$ ratio of chickens challenged with sheep erythrocytes post-treatment with Rhazya stricta. Values within the same day having the marks $*, * *, * * *$ are significantly different from control value at $\mathrm{p}<0.05, \mathrm{p}<0.01$, and $\mathrm{p}<0.001$, respectively. Mean \pm Standard error.

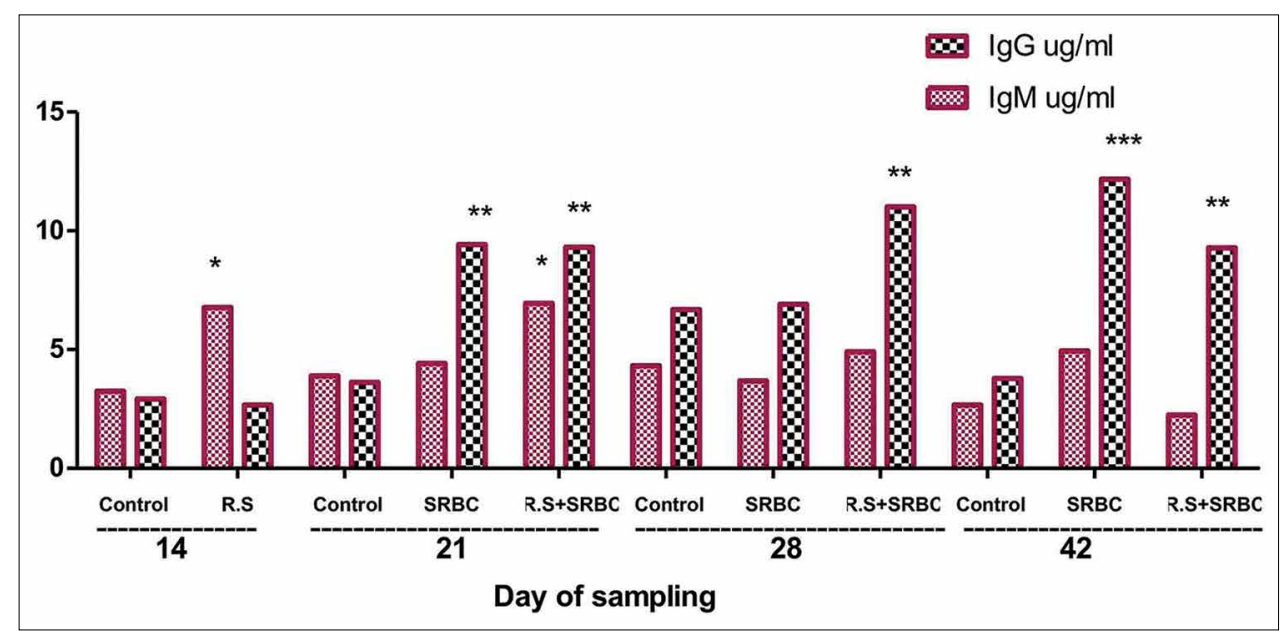

Figure-6: IgG (ug/mL) and IgM (ug/mL) of chickens challenged with sheep erythrocytes post-treatment with the Rhazya stricta extract. Values within the same day having the marks $*, * *, * * *$ are significantly different from the control value at $\mathrm{p}<0.05, \mathrm{p}<0.01$, and $\mathrm{p}<0.001$, respectively. Mean \pm Standard error.

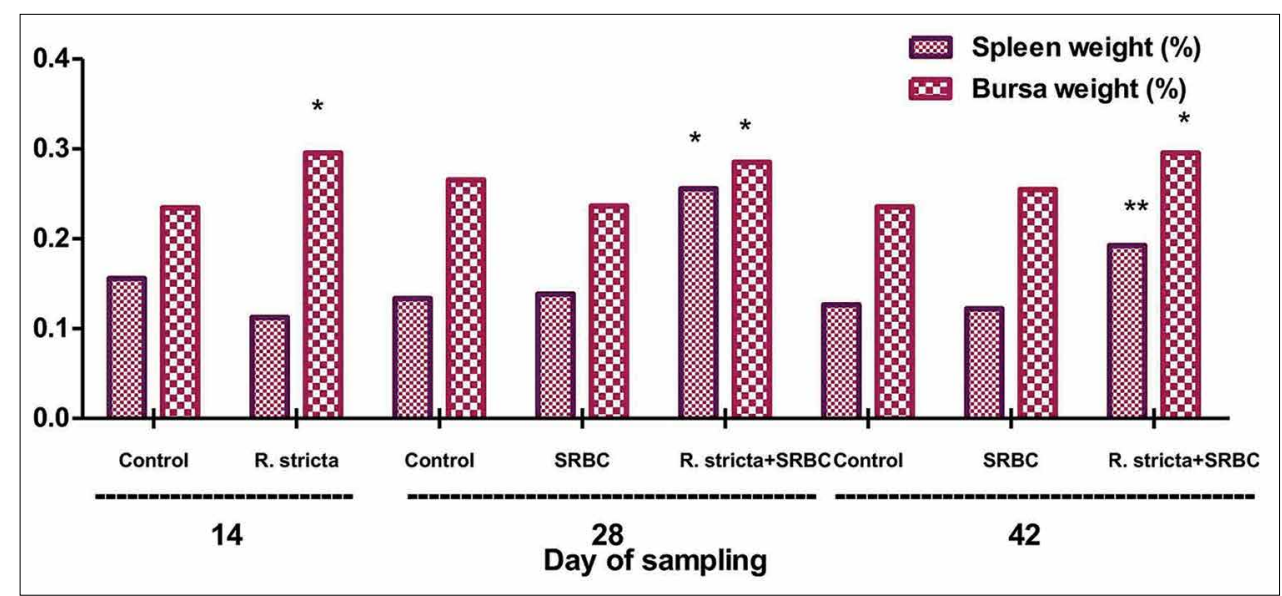

Figure-7: Relative weights of spleen and bursa chickens challenged with sheep erythrocytes following pretreatment with Rhazya stricta. Values within the same day having the marks $*, * *, * * *$ are significantly different from the control value at $\mathrm{p}<0.05, \mathrm{p}<0.01$, and $\mathrm{p}<0.001$, respectively. Mean \pm Standard error. 


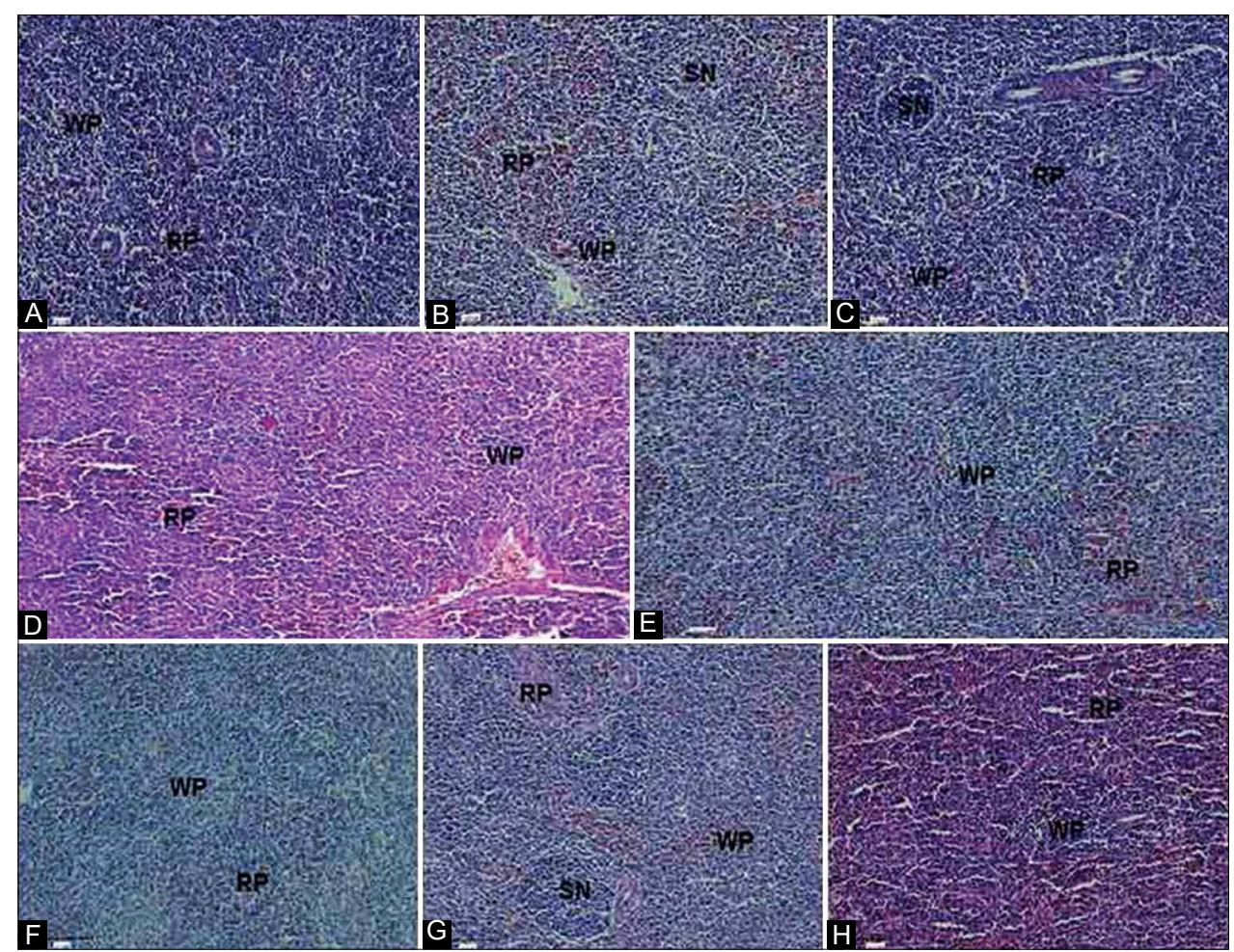

Figure-8: Histological structure of spleen of a control chicken on days 14 (A), 28 (B), and 42 (C), challenged with SRBC on days $28(\mathrm{D})$, and $42(\mathrm{E})$ and challenged with SRBC after supplementation with the Rhazya stricta extract on days $14(\mathrm{~F}), 28(\mathrm{G})$, and $42(\mathrm{H})$. (Hematoxylin and eosin 20x). RP: Red pulp, WP: White pulp, SN: Splenic nodule, SRBC: Sheep erythrocytes.

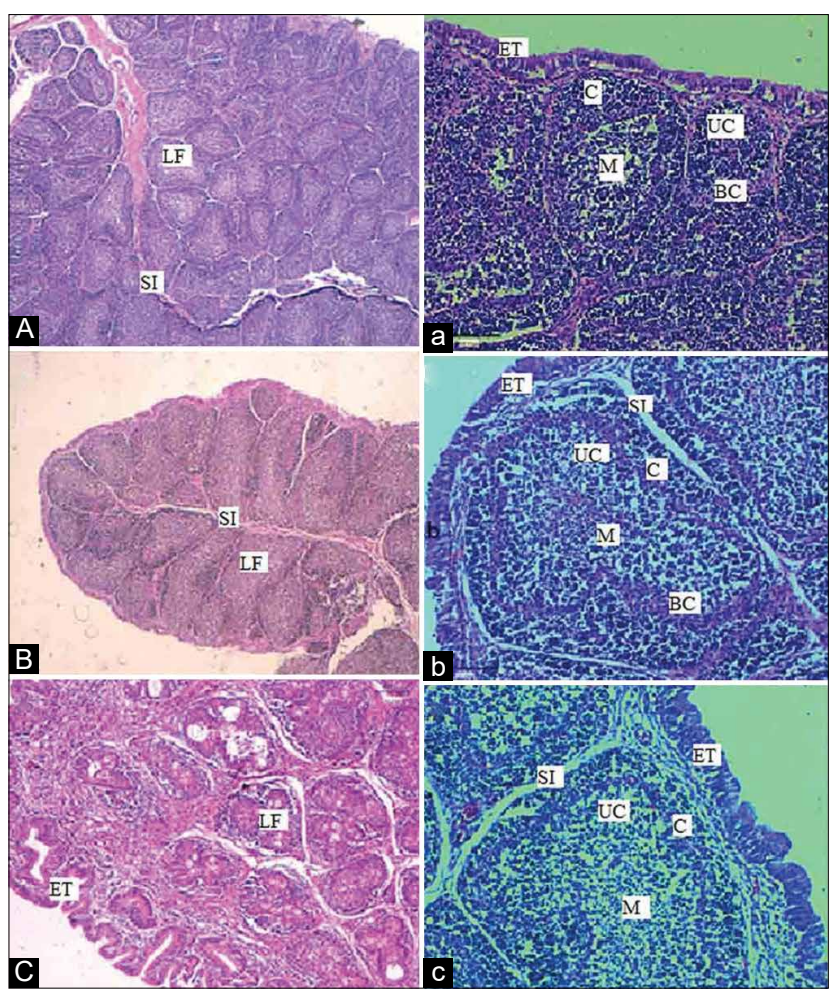

Figure-9: Histological structure of $\mathrm{BF}$ of a control chicken at three different ages $(14,28$, and 42$)$ with two magnifications. (A, B, C 4x) and (a, b, c 20x). SI: Space interfollicular, C: Cortex, M: Medulla, LF: Lymphoid follicle, ET: Epithelial tissues, UC: Undifferentiated cells, BC: Blood capillaries; BF: Bursa of fabricius.

glucose consumption tests, and histological examination of the spleen. We also measured the serum levels of the antioxidative enzymes to complete the assessment parallelogram. We recorded measurements of body weight gain, individual feed consumption, and feed conversion.

The TPC of the R. stricta extract and their antioxidant activities was $301.99 \pm 8.79$ and $38.05 \pm 6.58$, respectively (Figure-1). These values are considered high when compared to other plants, corresponding to a previous work by Iqbal et al. [36]. Iqbal et al. [36] have reported that the antioxidant capability of the methanolic extracts of $R$. stricta leaves was significantly elevated when compared to the $\alpha$-tocopherol or the synthetic antioxidant BHA [36]. Another study conducted in Saudi Arabia has demonstrated the high TPC of $R$. stricta extract [4], reporting that the plant exhibited a potent reducing antioxidant ability and free-radical scavenging capacity and recommended this plant for the treatment of certain diseases in humans.

As the chicks advanced in age, the weights of the $\mathrm{BF}$ and spleen significantly increased in the $\mathrm{SRBC}+R$. stricta group as compared to the control group. Body weight gain significantly increased in this group as well, significantly over that of the control group. The feed conversion rate tended to be lower in the control chicks as compared to the SRBCchallenged or $\mathrm{SRBC}+R$. stricta chicks.

No research has investigated the possible role of $R$. stricta as a growth promoter for chickens except for a single study by Al-Homidan et al. [37], who have shown that body weight gain and feed efficiency 


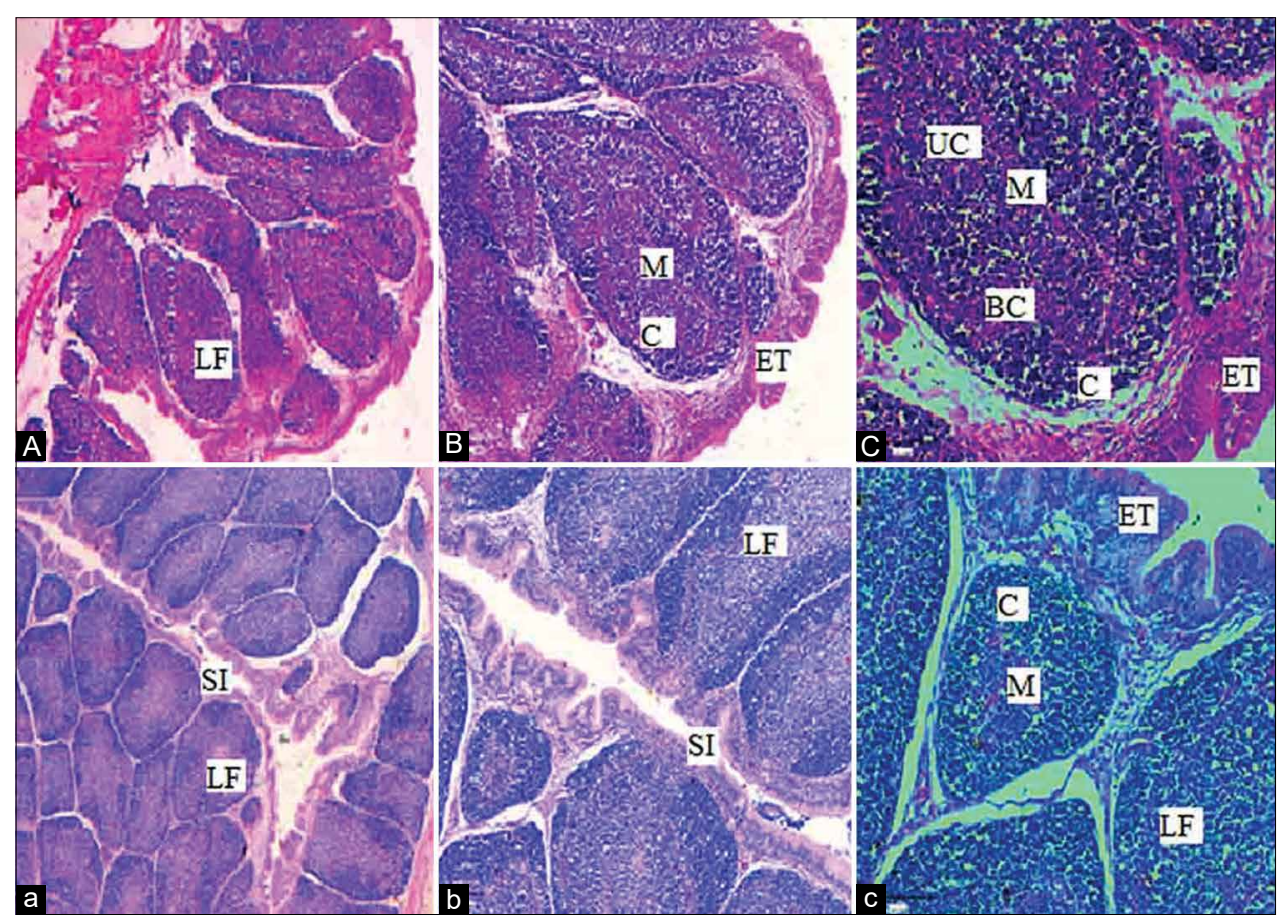

Figure-10: Hematoxylin-eosin staining for BF of a control chicken challenged with two doses of sheep erythrocytes. A, B, C of Bursa of Fabricius collected at day 28 with three magnifications $4 \times, 10 \times$, and $20 \times$, respectively. a, b, c of BF collected at day 42 with three magnifications $4 \times, 10 \times$, and 20x, respectively. SI: Space interfollicular, C: Cortex, M: Medulla, LF: Lymphoid follicle, ET: Epithelial tissues, UC: Undifferentiated cells, BC: Blood capillaries; BF: Bursa of fabricius.

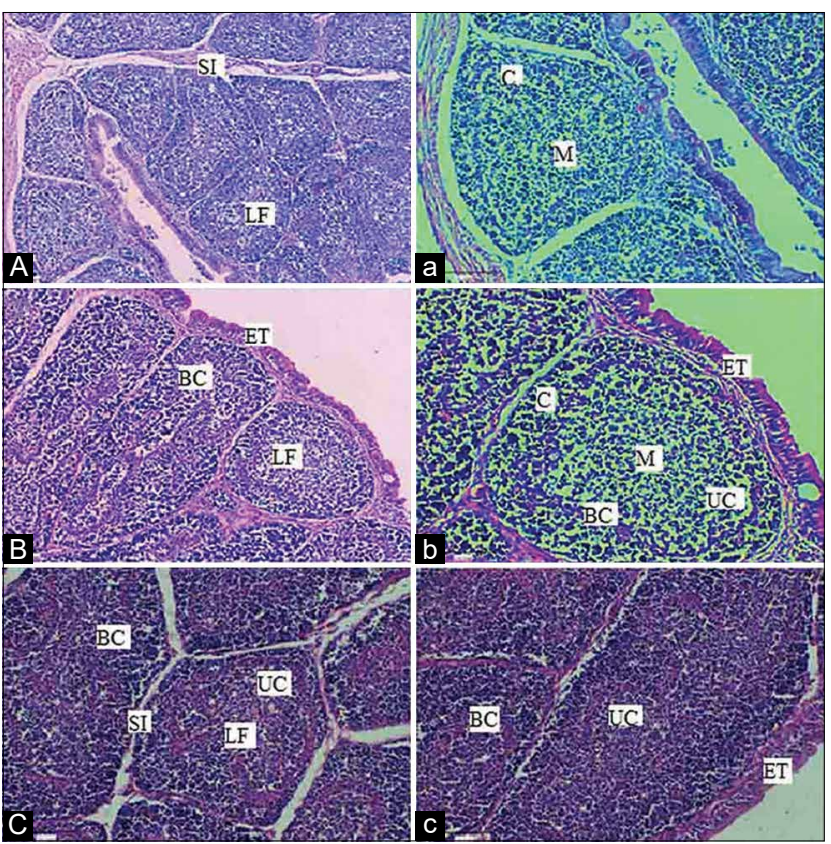

Figure-11: Hematoxylin and eosin staining for BF of chicken supplemented with the Rhazya stricta extract before the challenge with two doses of sheep erythrocytes. A, B, C: BF collected on days 14,28 , and 42 with $4 \times$, respectively. $a, b, c$ : BF collected on days 14,28 , and 42 with 20x, respectively. SI: Space interfollicular, C: Cortex, M: Medulla, LF: Lymphoid Follicle, ET: Epithelial tissues, UC: Undifferentiated Cells, BC: Blood capillaries; BF: Bursa of fabricius.

decreased after supplementation of $100 \mathrm{~g} / \mathrm{kg}$ R. stricta in chickens' diets. The contradictions between our findings and the results of Al-Homidan et al. [37] can be explained by the differences in dose, treatment duration, and supplementation type.
In the current study, we evaluated cellular immunity by assessing the in vitro phagocytic index, L proliferation, and leukogram. The results of the in vitro phagocytic index were significantly increased in the $\mathrm{SRBC}+R$. stricta group as compared to the control group on days 14,28 , and 42 . Because $\mathrm{H} \%$ was not affected by the $R$. stricta supplementation, the increase in the phagocytic index in the $\mathrm{SRBC}+R$. stricta group is likely due to enhancement in phagocytic activities rather than to an increase in the number of phagocytic cells. The phagocytic index has been shown to be significantly affected by the state of $\mathrm{N}$ [38].

Our data show that the amount of glucose consumed by Ls was significantly higher in the chicks challenged with SRBC regardless of $R$. stricta supplementation. However, glucose consumption by Ls of the $\mathrm{SRBC}+R$. stricta group was elevated as compared to Ls obtained from the SRBC-challenged group, suggesting that treatment with the $R$. stricta extract slightly enhances L proliferation. The results of the leukogram revealed significantly higher $\mathrm{L} \%$ and lower $\mathrm{H} / \mathrm{L}$ ratios on day 14 in the SRBC $+R$. stricta chicks relative to those of the control chicks. However, on days 28 and 42 , the results were similar, whereas we observed a significant increase in TLC, $\mathrm{H} \%$, and $\mathrm{M} \%$ in the SRBC-challenged chicks as compared to the control chicks. In addition, the L\% significantly increased and $\mathrm{H} / \mathrm{L} \%$ significantly decreased in the $\mathrm{SRBC}+R$. stricta chicks relative to the control chicks.

We examined the histology of the spleen to complete the assessment of the effects of $R$. stricta supplementation on cellular immunity. As the largest peripheral lymphoid organ, the spleen plays a key role 
in the immune system responses to bacterial and viral infections. The histological investigation revealed that the broiler spleen is surrounded by a thick splenic capsule and a few trabecula. The red pulp was less distinct and localized within the white pulp, composed mostly of RBCs. Ls of different sizes localized to the white pulp, which contains sheathed arteries and splenic nodules. The histological structures of the spleen in the present investigation correspond to those previously described [39].

In this study, we noted that the white pulp of the spleen increased in the $\mathrm{SRBC}+R$. stricta chicks as they advanced in age. As the chicks aged from days 14 to 42, different types of splenic nodules were easily visible. Our findings agree with the previous observations for white leghorn chickens [40].

We assessed the humoral arm of the immune system in the current investigation through the quantification of $\operatorname{Ig}(\mathrm{Abs})$ and examined the histological structure of the BF. In birds, the BF is an exceptional organ that grants immunity by providing a microenvironment for the cells of the immune system to develop, mature, and differentiate [41]. The BF contributes to the development of local immune responses by stimulating antibody production through antigens transported to the medulla [42]. However, the complexity of the BF starts at various ages of maturation [43].

The histological examination of the BF of the chicks in the control group revealed the presence of numerous lymphoid follicles on day 14 . The corticomedullary border, which contains undifferentiated cells and blood capillaries, divides the follicles into the cortex and medulla as previously described by Aughey and Fyre [43]. The cortex but not the medulla contained the capillary vessels with connective tissues, with the smooth muscular layer located under the mucosa surrounded by the T. serosa.

On day 28, the BF follicles appeared large and densely populated. The cortex was separated from the medulla by a basal membrane, visible in most sections. At the end of the experiment (day 42), the BF follicles appeared small, paler, and less densely populated, with scattered vacuoles. The separation between the cortex and medulla was thickened by connective tissue. At this age, this microscopic appearance is characterized as normal BF, as described by Tarek et al. [44]. The $\mathrm{BF}$ of SRBC $+R$. stricta chicks showed medullas with an extensive population of Ls, especially on day 42, suggesting that it is still active at this advanced age.

The injection of animals with foreign RBCs is a procedure used to examine the immunomodulatory impact and responses of the immune system without influencing animal well-being [45]. This type of challenge is commonly used in different species, especially to evaluate humoral immunity by determining the increase in antibody titers in response to foreign RBCs [45]. The RBC challenge has been used to quantify IgM and IgG titers in sheep [46], mice [46], and rabbits [47].
We measured Ig at different times using the ELISA technique. On day 14 , we noticed a significant increase in the IgM titers of the $\mathrm{SRBC}+R$. stricta chicks as compared to the control chicks. The SRBC challenge resulted in a significant increase in the IgG titers, with the IgM titers remaining significantly elevated only in the $\mathrm{SRBC}+R$. stricta group on day 21 relative to the control group. We saw a significant increase in the $\mathrm{IgG}$ titers in the $\mathrm{SRBC}+R$. stricta group on day 28 and in both the SRBC-challenged and $\mathrm{SRBC}+R$. stricta groups on day 42 as compared to the control group.

In poultry, the serum levels of IgM and IgG indicate modulation of humoral immunity and stimulation of the adaptive immune responses, as demonstrated by Makkar et al. [48]. Chicken IgM resembles its mammalian counterpart structurally and functionally, and it is the dominant isotype generated after the primary exposure to a new antigen $[49,50]$. Specific IgM responses increase after an initial encounter with an antigen, with responses decreasing following subsequent exposures. The IgM levels were significantly elevated only in the $\mathrm{SRBC}+R$. stricta group, suggesting that these chicks may be ready to respond to infections.

The avian IgG is the dominant isotype in the serum and is generated after the $\operatorname{IgM}$ isotype in the initial humoral response; $\mathrm{IgG}$ is the principal isotype in the subsequent humoral response [51]. The increase in the levels of $\operatorname{IgG}$ in the $R$. stricta-supplemented group may suggest a modulation in the humoral arm of the adaptive immune system, where these antibodies effectively contribute to protection against various microbial pathogens [52]. Therefore, biomedicine made from plant extracts may improve essential vital health conditions [53].

\section{Conclusion}

Supplementation of $18 \mathrm{mg} /$ chick from the aerial pieces of $R$. stricta (Harmal) in the drinking water of broiler chickens for 2 weeks shows an enhancement in cell-mediated and humoral immune responses. The results reported in this study highlight the potential use of this plant for therapeutic and preventive purposes. Further studies are needed to isolate its active composites and examine their mode of action against diseases.

\section{Authors' Contributions}

SMA: Designed and conducted the study, drafted and revised the manuscript, and approved the final manuscript

\section{Acknowledgments} study.

The authors did not receive any funds for this

\section{Competing Interests}

The author is thankful for Alwatanya Company for poultry, Al-Qassim, Saudi Arabia, for kindly providing the birds and their feeds. 


\section{Publisher's Note}

Veterinary World remains neutral with regard to jurisdictional claims in published institutional affiliation.

\section{References}

1. Dhama, K., Karthik, K., Khandia, R., Munjal, A., Tiwari, R., Rana, R., Khurana, S.K., Sana, U., Khan, R.U., Alagawany, M., Farag, M.R., Dadar, M. and Joshi, S.K. (2018) Medicinal and therapeutic potential of herbs and plant metabolites/extracts countering viral pathogens-current knowledge and future prospects. Curr. Drug Metab., 19(3): 236-263.

2. Gilani, S.A., Kikuchi, A., Shinwari, Z.K., Khattak, Z.I. and Watanabe, K.N. (2007) Phytochemical, pharmacological and ethnobotanical studies of Rhazya stricta Decne. Phytother. Res., 21(4): 301-307.

3. Adel, E.T., Mohamed, E.A., Attia, A.O. and El Dessoky, D.S. (2012) In vitro multiplication of the important medicinal plant, harmal (Rhazya stricta Decne). J. Med. Plants Res., 6(19): 3586-3590.

4. Bukhari, N.A., Al-Otaibi, R.A. and Ibhrahim, M.M. (2017) Phytochemical and taxonomic evaluation of Rhazya stricta in Saudi Arabia. Saudi J. Boil. Sci., 24(7): 1513-1521.

5. Obaid, A.Y., Voleti, S., Bora, R.S., Hajrah, N.H., Omer, A.M., Sabir, J.S. and Saini, K.S. (2017) Cheminformatics studies to analyze the therapeutic potential of phytochemicals from Rhazya stricta. Chem. Cent. J., 11(1): 11.

6. Baeshin, N.A., Sabir, J.S. and Qari, S.H. (2009) Cytogenetic and molecular evaluations of genetic effects of leaf extract of Rhazya stricta (Decne) on Allium cepa root tip meristems. Egypt. J. Genet. Cytol., 38(1): 73-83.

7. Alagrafi, F.S., Alawad, A.O., Abutaha, N.M., Nasr, F.A., Alhazzaa, O.A., Alharbi, S.N., Alkhrayef, M.N., Hammad, M., Alhamdan, Z.A., Alenazi, A.D. and Wadaan, M.A. (2017) In vitro induction of human embryonal carcinoma differentiation by a crude extract of Rhazya stricta. BMC Complement. Altern. Med., 17(1): 342.

8. Ahmed, A., Asad, M.J., Ahmad, M.S., Qureshi, R., Shah, S.I., Gul, H. and Gulfraz, M. (2015) Antidiabetic and hypolipidemic potential of Rhazya stricta Decne extract and its fractions. Int. Curr. Pharm. J., 4(2): 353-361.

9. Ahmad, A., Wei, Y., Ullah, S., Shah, S.I., Nasir, F., Shah, A., Iqbal, Z., Tahir, K., Khan, U.A. and Yuan, Q. (2017) Synthesis of phytochemicals-stabilized gold nanoparticles and their biological activities against bacteria and Leishmania. Microb. Pathog., 110(9): 304-312.

10. Nehdi, I.A., Sbihi, H.M., Tan, C.P. and Al-Resayes, S.I. (2016) Seed oil from Harmal (Rhazya stricta Decne) grown in Riyadh (Saudi Arabia): A potential source of $\delta$-tocopherol. J. Saudi Chem. Soc., 20(1): 107-113.

11. Ali, B.H., Al-Qarawi, A.A., Bashir, A.K. and Tanira, M.O. (2000) Phytochemistry, pharmacology and toxicity of Rhazya stricta Decne: A review. Phytother. Res., 14(4): 229-234.

12. Ali, B.H., Bashir, A.K. and Rasheed, R.A. (2001) Effect of the traditional medicinal plants Rhazya stricta, Balanitis aegyptiaca and Haplophylum tuberculatum on paracetamol-induced hepatotoxicity in mice. Phytother. Res., 15(7): 598-603.

13. Al-Hasawi, Z.M. and Al-Harbi, H.A. (2014) Effect of Rhazya stricta dense leaf extract on the liver and kidney tissue structure of albino mice. Global Adv. Res. J. Environ. Sci. Toxicol., 3(4): 57-64.

14. Bernstein, J.A., Liu, N., Knorr, B.A., Smugar, S.S., Hanley, W.D., Reiss, T.F. and Greenberg, S. (2011) MK-0633, a potent 5-lipoxygenase inhibitor, in chronic obstructive pulmonary disease. Respir. Med., 105(3): 392-401.

15. He, L., He, T., Farrar, S., Ji, L., Liu, T. and Ma, X. (2017)
Antioxidants maintain cellular redox homeostasis by elimination of reactive oxygen species. Cell. Physiol. Biochem., 44(2): 532-553.

16. Xu, D.P., Li, Y., Meng, X., Zhou, T., Zhou, Y., Zheng, J., Zhang, J.J. and Li, H.B. (2017) Natural antioxidants in foods and medicinal plants: Extraction, assessment and resources. Int. Mol. Sci., 18(1): 96.

17. Maarman, G.J. (2017) Natural antioxidants as potential therapy, and a promising role for melatonin against pulmonary hypertension. In: Pulmonary Vasculature Redox Signaling in Health and Disease. Springer, Cham. p161-178.

18. Meghwani, H., Prabhakar, P., Mohammed, S.A., Seth, S., Hote, M.P., Banerjee, S.K., Arava, S., Ray, R. and Maulik, S.K. (2017) Beneficial effects of aqueous extract of stem bark of Terminalia arjuna (Roxb.), An ayurvedic drug in experimental pulmonary hypertension. J. Ethnopharmacol., 197(2): 184-194.

19. Simioni, C., Zauli, G., Martelli, A.M., Vitale, M., Sacchetti, G., Gonelli, A. and Neri, L.M. (2018) Oxidative stress: Role of physical exercise and antioxidant nutraceuticals in adulthood and aging. Oncotarget, 9(24): 17181.

20. Saeed, S.A., Simjee, R.U., Mahmood, F. and Sultana, N. (1993) Rhazimine from Rhazya stricta: A dual inhibitor of arachidonic acid metabolism and platelet-activating factor-induced platelet aggregation. Planta Med., 59(6): 566-567.

21. Tanira, M.O.M., Ali, B.H., Bashir, A.K., Wasfi, I.A. and Chandranath, I. (1996) Evaluation of the relaxant activity of some United Arab Emirates plants on intestinal smooth muscle. J. Pharm. Pharmacol., 48(5): 545-550.

22. Ali, B.H., Alqarawi, A.A., Bashir, A.K. and Tanira, M.O. (2000) Antioxidant action of extract of the traditional medicinal plant Rhazya stricta Decne. in rats. Phytother. Res., 14(6): 469-471.

23. Baeshen, N.A, Lari, S.A, Aldoghaither, H.A. and Elkady, A.I. (2010a) Biochemical evaluation of the effect of Rhazya stricta aqueous leaves extract in liver and kidney functions in Rats. Nat. Sci., 8(4): 136-142.

24. Baeshen, N., Lari, S., Al Doghaither, H.A. and Ramadan, H.A. (2010b) Effect of Rhazya stricta extract on rat adiponectin gene and insulin resistance. $J . A m$. Sci., 6(12): 1237-1245.

25. Elkady, A.I., Hussein, R.A. and Abu-Zinadah, O.A. (2014) Differential control of growth, apoptotic activity and gene expression in human colon cancer cells by extracts derived from medicinal herbs, Rhazya stricta and Zingiber officinale and their combination. World J. Gastroenterol., 20(41): 15275.

26. Patwardhan, B., Kalbag, D., Patki, P.S. and Nagsampagi, B.A. (1990) Search of immunomodulatory agents: A review. Indian Drugs, 28(2): 56-63.

27. Soumya, V., Muzib, Y.I., Venkatesh, P. and Hariprasath, K. (2014) GC-MS analysis of Cocos nucifera flower extract and its effects on heterogeneous symptoms of polycystic ovarian disease in female Wistar rats. Chine. J. Nat. Med., 12(9): 677-684.

28. Lu, J., Zhao, H., Chen, J., Fan, W., Dong, J., Kong, W., Sun, J., Cao, Y. and Cai, G. (2007) Evolution of phenolic compounds and antioxidant activity during malting. J. Agric. Food Chem., 55(26): 10994-1001.

29. National Research Council. (1994) Nutrient Requirements of Poultry. $9^{\text {th }}$ ed. National Academy Press, Washington, DC, USA.

30. Alharbi, K.B., Mousa, H.M., Ibrahim, Z.H. and El-Ashmawy, I. (2017) Hepatoprotective effect of methanolic extracts of Prosopis farcta and Lycium shawii against carbon tetrachloride-induced hepatotoxicity in rats. J. Biol. Sci., 17(1): 35-41.

31. Trombetta, C.M., Ulivieri, C., Cox, R.J., Remarque, E.J., Centi, C., Perini, D., Piccini, G., Rossi, S., Marchi S. and Montomoli, E. (2018) Impact of erythrocyte species on assays for influenza serology. J. Prev. Med. Hyg., 59(1): E1-E7 
32. Spinu, M. and Degen, A.A. (1993) Effect of cold stress on performance and immune responses of Bedouin and White Leghorn hens. Br. Poult. Sci., 34(1): 177-185.

33. Kosti, O., Byrne, C., Cocilovo, C., Willey, S.C. and Zheng, Y.L. (2010) Phytohemagglutinin-induced mitotic index in blood lymphocytes: A potential biomarker for breast cancer risk. Breast Cancer, 4(1-12): 73-83.

34. Jain, N.C. (1986) Veterinary Hematology. $4^{\text {th }}$ ed. Lea and Fabiger, Philadelphia, PA, United States.

35. Guo, L., DeRoche, T.C., Salih, Z.T. and Qasem, S.A. (2018) Routine hematoxylin and eosin stain is specific for the diagnosis of cytomegalovirus infection in gastrointestinal biopsy specimens. Int. J. Surg. Pathol., 26(6): 500-506.

36. Iqbal, S., Bhanger, M.I., Akhtar, M., Anwa, F., Ahmed, K.R. and Anwer, T. (2006) Antioxidant properties of methanolic extracts from leaves of Rhazya stricta. J. Med. Food, 9(2): 270-275.

37. Al-Homidan, A., Al-Qarawi, A.A., Al-Waily, S.A. and Adam, S.E. (2002) Response of broiler chicks to dietary Rhazya stricta and Nigella sativa. Br. Poult. Sci., 43(2): 291-296.

38. Dey, A., Allen, J. and Hankey-Giblin, P.A. (2015) Ontogeny and polarization of macrophages in inflammation: Blood monocytes versus tissue macrophages. Front. Immunol., 5(1): 683 .

39. Hodges, R.D. (1974) The Histology of the Fowl. Academic Press, United States.

40. Khan, M.Z., Hashimoto, Y. and Asaduzzman, M. (1998) Development of T-cell sub-populations in postnatal chicken lymphoid organs. Vet. Arhiv., 68(5): 183-189.

41. Martelli, D., Farmer, D.G. and Yao, S.T. (2016) The splanchnic anti-inflammatory pathway: Could it be the efferent arm of the inflammatory reflex? Exp. Physiol., 101(10): 1245-1252.

42. Olah, I. and Glick, B. (1992) Follicle-associated epithelium and medullary epithelial tissue of the bursa of Fabricius are two different compartments. Anatom. Record, 233(4): 577-587.

43. Aughey, E. and Frye, F.L. (2001) Comparative Veterinary Histology with Clinical Correlates. CRC Press, United States.
44. Tarek, K., Mohamed, M., Hassina, B. and Messaouda, I. (2013) Histological study of the bursa of Fabricius of broiler chickens during heat stress. Int. J. Poult. Sci., 12(6): 377-378.

45. Geng, T., Guan, X. and Smith, E.J. (2015) Screening for genes involved in antibody response to sheep red blood cells in the chicken, Gallus gallus. Poult. Sci., 94(9): 2099-2107.

46. McAllister, E.J., Apgar, J.R., Leung, C.R., Rickert, R.C. and Jellusova, J. (2017) New methods to analyze B cell immune responses to thymus-dependent antigen sheep red blood cells. J. Immunol., 199(8): 2998-3003.

47. Qiu, C.F., Lei, L.S., Wu, Y.Y., Yu, C.L., Zhu, Z.G., Chen, N.N. and Wu, S.G. (2009) Establishment of mouse model of humoral immune response using rabbit red blood cells as the antigen. J. Southern Med. Univ., 29(12): 2473-2476.

48. Makkar, S., Rath, N.C., Packialakshmi, B., Huff, W.E. and Huff, G.R. (2015) Nutritional effects of egg shell membrane supplements on chicken performance and immunity. Poult. Sci., 94(6): 1184-1189.

49. Grönwall, C., Silverman, G.J. and Natural, I.G.M. (2014) beneficial autoantibodies for the control of inflammatory and autoimmune disease. J. Clin. Immunol., 34(1): 12-21.

50. Ehrenstein, M.R. and Notley, C.A. (2010) The importance of natural IgM: Scavenger, protector and regulator. Nat. Rev. Immunol., 10(11): 778-786.

51. Aboelsoued, D., Abo-Aziza, F.A.M., Mahmoud, M.H., Abdel Megeed, K.N., Abu El Ezz, N.M.T. and AbuSalem, A.M. (2019) Anticryptosporidial effect of pomegranate peels water extract in experimentally infected mice with special reference to some biochemical parameters and antioxidant activity. J. Parasit. Dis., 43(2): 215-228.

52. Jeurissen, S.H. (1993) The role of various compartments in the chicken spleen during an antigen-specific humoral response. Immunology, 80(1): 29.

53. Dhama, K., Latheef, S.K., Mani, S., Abdul Samad, H., Karthik, K., Tiwari, R., Khan, R.U., Alagawan, M., Farag, M.R., Alam, G.M., Laudadio, V. and Tufarelli, V. (2015) Multiple beneficial applications and modes of action of herbs in poultry health and production-a review. Int. J. Pharmacol., 11(3): 152-176. 